\title{
Research on the Coordination of National Fitness Resources in the Old Revolutionary Area of Jiangxi
}

\author{
Baoyan Fu \\ Jiangxi Teachers College, Yingtan, Jiangxi, China \\ fubaoyan80@126.com
}

Keywords: Revolutionary Old Area, National Fitness, Resource Coordination

\begin{abstract}
In the construction of new socialist countryside, the development of rural ecological background, through empirical analysis of Jiangxi rural cooperative revolutionary national fitness sports resources, find out the revolutionary groups and administrative villages in the health sports resources demand management coordination mechanism coordination and control mechanism to explore public health resources, the old revolutionary base areas the masses have understanding and more comprehensive understanding of the national fitness, so as to change their concept of sports consumption, sports values, enhance people's awareness of national fitness, enhance people's sports health index. The article suggests: in the old revolutionary base of Jiangxi national fitness resources collaborative in the practical implementation of the "National Fitness Program", "national fitness regulations", "health Chinese 2030 plan", through Internet technology, collaborative development of sports market development and construction of rural health integration of public sports resources, construction of grass-roots sports and improve the management system, strengthen the sports fitness related good publicity to raise people's awareness of sports fitness, broaden the sources of funding, through the Internet for the area to carry out "the sports festival", the development of folk traditional sports, in order to strengthen the implementation of the national fitness place, driven by Jiangxi old revolutionary local sports and social, economic and cultural development.
\end{abstract}

\section{The Purpose}

The overall health of the nation is crucial to the development of the country. In 1995, the Chinese State Council issued the outline of the national fitness program, which reflects the government attention to the health of the citizens. However, the current situation of public fitness in China is worth serious consideration, especially the rural sports development of the people's foundation is very weak. More than 900 million of the rural population in China, if there is no rural sports development, then the mass sports will not develop. Research on rural public health campaign resources synergy and Internet sports poverty alleviation is very important for developing "farmer fitness project", which can promote the development of rural fitness activities and enhance the health level of villagers. In 2011, the Chinese State Council issued the "National Fitness Program (2011-2015 years)" in the notice emphasized the need to accelerate the development of rural sports, the development of rural sports development for the construction of new socialist countryside construction planning, coordinating the development of rural public health undertakings, promote the balanced allocation of sports resources and the construction of public sports service the national fitness public service system, improve the level of rural public sports service. Comprehensive service facilities play good rural community utility, sports facilities and sports talents to make full use of "rural schools" and "enterprises" and other resources, to carry out "the sports and sports activities to the countryside" in our traditional festivals and the slack season, a solid grasp of the peasant sports meeting. Most of China's rural sports consciousness culture is lagging behind the city, in advocating the development of ecological rural background, improve farmers' fitness consciousness, promote health, public health campaigns to promote resource collaborative development, through the Internet in sports media, training, industry, facilities, environment, network, stadiums and other aspects of the 
information intelligence support for projects to achieve the impoverished rural sports poverty.

\section{The significance and thought of the paper}

As the breakthrough point of the public health resources background of Jiangxi province revolutionary areas ecological rural development under the perspective of poverty and collaborative Internet sports, follow the "National Fitness Program", "national fitness regulations", "health China 2030 plan" advocated by the rational use of resources, on the basis of the realization of the overall sports resources in the area of science efficient management for rural public by the ideas to the ways and methods of change, in the premise to ensure the ecological development of the country, make full use of resources, rational allocation, take a "regional sports resources" coordinated development "drive area sports, fitness activities development, give effective development ideas for the better development of regional national public health, to provide a reference for our country national fitness. Follow the "forward - Analysis - to solve the problem of conventional thinking, methods of theoretical, empirical, the relevant research data at home and abroad were summarized, pointed out that the synergy exists in the rural public sports resources ecological health issues, poverty alleviation and strong support in the Internet sports media, sports training, industry, infrastructure, environment, project, digital and intelligent" etc.

\section{Methods}

\subsection{Document}

In CNKI, Wan Fang and other databases, we searched and retrieved relevant research data from 2005 to 2017, including sports resources, regional resources, resources development and national fitness. We carefully study of the national sports colleges and universities of the Journal of sports resources, Internet sports poverty alleviation, national fitness and other articles related to more than 200 articles. A large number of relevant books and materials have been read in the library of Jiangxi normal college.

\subsection{Questionnaire survey}

The existing related literature review and questionnaire, and the expert on the view, and finally determine the village concept, population, public health facilities, market, funds, organization, guidance and information services, as the main index of national fitness sports resources, survey design of the old revolutionary base areas of rural public sports resources ecological Health Study on the Internet sports poverty alleviation collaboration. 1200 questionnaires were issued and reclaimed, 1070 were recovered and 1000 were valid. The efficiency reached $83.3 \%$.

Table 1 Distribution and recovery of questionnaires

\begin{tabular}{cccccc}
\hline questionnaires & total & recovery & recovery & $\begin{array}{c}\text { effective } \\
\text { questionnaires }\end{array}$ & effective \\
\hline 1200 & 1070 & $89.1 \%$ & 1000 & $83.3 \%$ \\
\hline
\end{tabular}

\subsection{Expert interview}

In the process of research, we interviewed with experts from national fitness and sports management, and collected various qualitative data. At the same time, the group interviewed the Jiangxi revolutionary old district education bureau and the relevant leaders of the Sports Bureau. Aiming at the purpose and content of the research, we know the current situation and existing problems of national fitness in interviews with experts and scholars in sports laws, regulations and management.

\section{The definition and present situation of the relevant concepts} 4.1 The concept of public health sports resources

Public health resources means to enhance citizen physique, promote health and the establishment of the "public sports venues and sports equipment, its development of human beings enjoy the natural material for health and provide the necessary public health conditions, resource ownership of public 
health, for all members of the society share together, to promote the healthy development of social groups shared by basic sports resources.

\subsection{The coordination of physical fitness resources for national citizens}

The national fitness sports resources coordination and means in order to help our "poor areas" to carry out sports activities, and then through the information network and information publishing technology and attracting sports related information on the Internet, to change the area lack of sports resources through the information project promotion mode. The Internet sports poverty alleviation adopted by information technology has "near and far" plan and definite sports fitness activities development goals, and corresponding plans and measures are drawn up for the purpose of sports planning. It is the organic combination of "managing the standard and managing the standard" in the work of poverty alleviation. Under the information technology of the Internet sports poverty, not only help a unit area and by the development of local sports, promote regional culture, but sports can also effect of stimulating the local economy. Internet sports poverty alleviation can mobilize all relevant government departments and all sectors of society to cooperate with each other to provide sports related resources to help the needs of units and regions.

\subsection{Present situation of sports population in revolutionary old area}

The criteria of the sports population are: weekly physical fitness activities frequency is greater than or equal to 3 times; each time fitness is greater than or equal to $30 \mathrm{~min}$; each strength more than moderate. Based on the basis of previous studies, adopting new criteria: in a year's time in line with the above 1 criteria for a situation, as the "general sports population"; with 2, as the "standard sports population"; with 3, as the "sports population", meet 0 conditions, as non Sports population". For details, see Table 2. The total number was 1000, of which 368 were male and 632 were female.

Table 2 the state of physical fitness and physical fitness in revolutionary old areas $(n=1000)$

\begin{tabular}{c|c|c|c|c|c}
\hline Gender & $\mathrm{n}$ & $\begin{array}{c}\text { non standard } \\
\text { sports population } \\
(\%)\end{array}$ & $\begin{array}{c}\text { general sports } \\
\text { population (\%) }\end{array}$ & $\begin{array}{c}\text { Secondary } \\
\text { standard sports } \\
\text { population (\%) }\end{array}$ & $\begin{array}{c}\text { Standard } \\
\text { sports population } \\
(\%)\end{array}$ \\
\hline Men & 368 & $180(48.91)$ & $89(24.18)$ & $69(18.75)$ & $30(8.52)$ \\
Women & 632 & $378(59.81)$ & $158(25)$ & $64(10.26)$ & $32(5.06)$ \\
\hline
\end{tabular}

\subsection{Sports consumption status of revolutionary old area}

The result indicates that no consumption of the largest population, accounting for $36.8 \%$ of the total, the backward rural economy is the main cause of non consumption, mostly rely mainly on crops, farmers' income is single, less than $200 \mathrm{RMB}$ is the leading consumer groups, accounted for $37.6 \%$ of the total number of more than $500 \mathrm{RMB}$, also accounted for a considerable proportion, accounting for the total number of $11.6 \%$, the main reason of this phenomenon is the sports consumption level higher village, development of "Nong jia le" and three industry, increase the income of farmers, enhance the consciousness to strengthen health.

Table 3 sports consumption level $(\mathrm{n}=1000)$

\begin{tabular}{lcccccccc}
\hline Ratio & 0 & $<50$ & $51-100$ & $101-200$ & $201-300$ & $301-400$ & $401-500$ & $>500$ \\
\hline $\mathrm{n}$ & 368 & 132 & 121 & 123 & 76 & 35 & 29 & 116 \\
$\%$ & $36.8 \%$ & 13.2 & $12.1 \%$ & $12.3 \%$ & $7.6 \%$ & $3.5 \%$ & $2.9 \%$ & $11.6 \%$ \\
\hline
\end{tabular}

\subsection{Sports events in revolutionary old area}

The highest frequency of walking participation is $58.9 \%$, which is mainly due to the road of village, which provide the condition for the walk after the meal. Chess and card for mental sports, no technical requirements, no field restrictions, neighbors, friends in the home can carry out chess and card activities. The outdoor apparatus area fitness, the fitness design is reasonable, the equipment 
combination can exercise to the person's whole body, it is the fitness project that the villagers prefer. Dance is popular in recent years. A simple collective sports, sports fitness programs and suitable men and women, regardless of the city or village and high streets and back lanes, the villagers in the yard, can carry out whenever and wherever possible. Basketball competitions are carried out every year. Athletes from different towns are selected by various towns. The township teams are selected from various natural villages. Basketball matches can promote the development of basketball, and can't be popularized by restrictions such as venues. Mountaineering, dragon accounted for respectively $7.8 \%$ and $5.7 \%$, the villagers in spare time will be climbing. The dragon dance is generally an invitation to perform during the holidays and major activities. Football is the last of all the research project, the main reason is that football has a high requirement for both technology and field.

\section{Countermeasures and suggestions}

\subsection{Construction of the management mechanism of Internet sports poverty alleviation in the ecological rural areas of the revolutionary old areas}

The education level of the rural population is low, and the traditional agricultural management habits are followed. As for the understanding of physical fitness, it is still believed that the daily work of farm work is a physical exercise. Through the collection and management of the data information of the above-mentioned sports resources, all kinds of data are integrated through the cloud service model to generate the data management system. For example, through data sorting, establish and improve the network sports information project management mechanism, the following modules can be created: 1) to create a manager learning block. Make full use of the Internet information sharing, collect sports management related information, for the sports managers to learn, improve their management level and professional quality. In this way, the purpose of learning can be achieved without going out of the house. At the same time, we use Internet information technology to publish information about sports management related lectures and information scholars in the old revolutionary base areas, and attract volunteers from sports management major to teach free. 2) We create a recruitment block. The technical guidance information of blue ball, football and other related sports items is issued, and the social sports instructors are recruited through the network information technology. In the absence of funds, through the Internet, we need to publish relevant information about social sports instructors in the old revolutionary base areas, attract sports related professionals, and volunteer villages for villagers' basketball, football and other sports technical guidance. 3) We also create a stadium and a facility layout. We should publicize the related sports venues, for example, we can vigorously support village level clubs through information network, expand their popularity, pay attention to sports publicity, publish early plans and activities records, and make use of the network information project mode to achieve the advertising effect. We can also publish the required sports facilities on the block and attract the charitable people to make no contribution to the rural areas such as other revolutionary old areas.

\subsection{Increase and promote the villagers' consciousness of physical fitness}

The study found that $57.6 \%$ of the villagers chose the choice of productive labor over physical fitness. Therefore, it is necessary to teach the villagers to teach the importance of physical exercise, to reverse their misconceptions and to guide the villagers to set up a correct concept of fitness. Make full use of Internet technology to carry out propaganda, popularize sports knowledge to the villagers, the villagers arouse the awareness of fitness, fitness content of the Internet information technology sports poverty advocacy, can be tailored for the villagers, and put forward the catchy "sports slogan", excited villagers to participate in physical exercise. Through the Internet access to information technology to carry out scientific publicity, in the blood of the villagers into the concept of fitness, mobilize the enthusiasm of the villagers to participate in fitness. The Internet promotes "scientific and healthy" fitness programs and techniques. Therefore, the farmer consumption level is low, sports consciousness of the problem, the need for appropriate publicity through the Internet, WeChat circle and other information technology in a variety of ways, namely take publicity and consultation 
activities of different levels and different mode, promote the villagers awareness of physical fitness promotion.

\subsection{Fitness guidance strategy}

The ratio of participating in the dance for $33.7 \%$, ranking fourth in the ten activities, that is loved by the villagers dance. However, the villagers of dance, limited income, although no money please love dance teachers, through the Internet information technology, to attract professional people to dance, video or sports into the village poverty alleviation model for the villagers compulsory dance teaching. There is a dance video or teachers for home teaching, love the villagers dance will naturally have a great enhancement to fitness, and actively devoted to physical fitness, and persevere to go. At present, rural youth sports training is also very weak, because the market share is small, there are very few sports training institutions in the township. In this case, we can seek training teachers across the country through the Internet technology.

\subsection{Strengthen the development and construction of the sports market}

In view of natural sports resources, human sports resources, venues and facilities, sports resources, information sports resources, funding sports resources, organization sports resources and industrial sports resources and other public health sports resources, the development and construction of sports market will be coordinated. Adopt policy system safeguard measures. Along with the rapid development of the rural economy, improve the quality of life of the peasants, suburban villagers to participate in the sports fitness enthusiasm growing, sports awareness and enhance the level of consumption, and promote the rural sports market boom, to meet the needs of the sports fitness of villagers, increase physical construction, is the focus of attention to the local sports related institutions and the government.

\subsection{Increase the government's measures on the whole people's health service system}

The national health service system, which means governments at all levels in order to ensure that the people enjoy sports rights, to meet the growing demands of sports service, network information service system of investment funds for the construction of public sports venues and facilities, construction of sports system, establishment of the public nature of public sports organization network, social sports instructors, to support the construction, construction the operation and evaluation of the core content of fitness service system. The national fitness service system includes the system of "community sports service, organization service, fitness equipment and facilities services, fitness service, financial support services, information services" and so on. The main task of the organization service system is to carry out the national fitness activities effectively, and organize unified planning effectively. In order to achieve scientific and reasonable planning, we can also effectively serve.

\section{References}

[1] Lu Changfen. The investigation and analysis on the status of urban migrant workers participating in national fitness [J]. Journal of Tianjin University of Sport, 2005,5 (6): 10-12.

[2] Li Yanling. Theory and method of sports scientific research [M]. Hunan literature and Art Press, 2003.

[3] Zhu Joan. The national fitness program introduction and [M]. sports history.1995. 3. 15-17.

[4] $\mathrm{Hu}$ Xiuying. Construction of a harmonious society on the development of new rural sports [J]. Journal of Shanxi Normal College of physical education, 2010.25 (1): 54-56.

[5] Lu Yuanzhen. Sports sociology [M]. Beijing. Higher education press, 2001.

[6] Wu Feng. Countermeasures for the development of rural sports from the perspective of humanistic care [J]. sports and science, 2009, 30 (1): 51-53.

[7] Cheng Huaping on the role of South of Jiangsu Township sports competition in the construction of new countryside [J]. Journal of Mudanjiang Normal College 2010.70 (1): 39-41.

[8] Dong Xinguang. Several problems in the construction of public health service system for all people [Z] ten training classes for mass sports, 2012. 
[9] Liu Xiaobin. Some thoughts on the implementation of the national fitness program in rural China [[J]. supplement 2015.1 (11) of the Journal of Chengdu Sport University (11): 4-6.

[10] Tang Shiwei Liu Xianmei. "Information theory" [M]. Harbin Engineering University press, 2009. 